\title{
Changes in visual function and quality of life in patients with senile cataract following phacoemulsification
}

\author{
Lijun He", Yinjuan Cui", Xiaoli Tang, Shu He, Xiaoyan Yao, Qin Huang, Haiyan Lei, Hui Li, Xuan Liao \\ Department of Ophthalmology, Affiliated Hospital of North Sichuan Medical College, Nanchong, China \\ Contributions: (I) Conception and design: L He, Y Cui, X Liao; (II) Administrative support: X Tang, X Liao; (III) Provision of study materials and \\ patients: L He, Y Cui, S He, X Yao, Q Huang; (IV) Collection and assembly of data: All authors; (V) Data analysis and interpretation: L He, X Liao, \\ X Tang, S He, H Lei, H Li, X Liao; (VI) Manuscript writing: All authors; (VII) Final approval of manuscript: All authors. \\ "These authors contributed equally to this work. \\ Correspondence to: Xuan Liao. Department of Ophthalmology, Affiliated Hospital of North Sichuan Medical College, Nanchong, China. \\ Email: hejingxianming@163.com.
}

Background Phacoemulsification is the accepted first-line treatment for cataracts. This study aims to explore the changes in visual function and quality of life in patients with senile cataracts following phacoemulsification, and its risk factors.

Methods: The clinical data of 104 patients (202 eyes in total) with senile cataract who underwent phacoemulsification in our hospital from August 2017 to August 2019 were retrospectively analyzed, and finally 102 cases (198 eyes) were enrolled according to the inclusion and exclusion criteria. These eyes were divided into the low vision group $(n=75)$ and non-low vision group $(n=123)$ The changes in pre- and post-operative visual function and quality of life of patients were compared. Logistic regression was used to analyze the risk factors of visual function of patients with senile cataract after phacoemulsification. The correlation between visual function and quality of life was examined.

Results: The postoperative subjective vision, peripheral visual field, visual adaptation, and stereo vision scores, as well as the total score were higher at both 3 days and 3 months compared to the preoperative scores $(\mathrm{P}<0.05)$. Also, the postoperative self-care ability, mobility, psychological states, and social ability scores, as well as the total scores were higher at both 3 days and 3 months than the preoperative scores $(\mathrm{P}<0.05)$. Age $(\geq 80)$, preoperative corrected visual acuity $(<0.1)$, a history of glaucoma, postoperative corneal edema, fundus lesions, and a longer phacoemulsification time were independent risk factors affecting the visual function of patients with senile cataract following phacoemulsification $(\mathrm{P}<0.05)$. The visual function indexes of patients were positively correlated with the quality of life $(\mathrm{P}<0.05)$.

Conclusions: Phacoemulsification can improve the short-term visual function of patients with senile cataract and improve their quality of life. Advanced age, preoperative corrected visual acuity $(<0.1)$, a history of glaucoma, postoperative corneal edema, fundus lesions, and a longer phacoemulsification time are independent risk factors that affect the visual function of patients with senile cataract after phacoemulsification. For patients with the aforementioned high-risk factors, enhanced clinical intervention and evaluation is required to reduce the risk of poor postoperative vision.

Keywords: Senile cataract; phacoemulsification; visual function; quality of life; independent risk factors

Submitted Aug 04, 2020. Accepted for publication Sep 25, 2020.

doi: 10.21037/apm-20-1709

View this article at: http://dx.doi.org/10.21037/apm-20-1709 


\section{Introduction}

Cataract is a degenerative change in lens metabolism and is typically characterized by a clouding of the lens. It has various underlying causes and is often related to a reduction in optical quality caused by attenuation in lens clarity and change in lens color (1). Cataracts are more prevalent in middle-aged and elderly people ( $>40$ years old), and the incidence increases with age. Symptoms of cataracts typically include lens opacity, painless vision loss, blurred vision, and other visual impairments that usually affect both eyes. These symptoms have a significant impact on the quality of life of patients to varying degrees (2).

However, given that there are no pharmacological treatments available to prevent, delay, or cure cataracts, surgical intervention has become the first-line therapeutic option for this disease. The ultimate goal of treatment is to improve the visual function and survival of patients. The clinical subjective visual function and quality of life scale (QQL) are used as important indicators to evaluate the efficacy of surgery. Presently, phacoemulsification coupled with intraocular lens implantation is the prevailing surgical method for the treatment of cataracts. However, despite its advantages, including the minor incision and the rapid postoperative recovery of vision and vision-related functional activities, there remain some cases of poor postoperative visual function following phacoemulsification (3). In this study, we investigated the changes in visual function and quality of life after phacoemulsification in patients with senile cataracts to provide new ideas for clinical treatment. We present the following article in accordance with the MDAR reporting checklist (available at http://dx.doi.org/10.21037/apm-201709).

\section{Methods}

\section{General clinical information}

Clinical data of 104 senile cataract patients (202 eyes in total) who underwent phacoemulsification in our hospital from August 2017 to August 2019 were retrospectively analyzed. With the inclusion criteria of: (I) patients aged $\geq 60$ years old; (II) patients diagnosed with cataract; (III) patients who had undergone phacoemulsification of cataract combined with intraoperative implantation of blue light-filter intraocular lenses (IOLs); (IV) patients that consciously accepted the quality of life survey; (V) patients' clinical data was complete and true. Exclusion criteria: (I) patients with corneal, fundus, or other diseases that affect vision (i.e., other than cataracts); (II) patients with mental diseases. Finally, 102 cases (198 eyes) were enrolled as study objects according to the inclusion and exclusion criteria.

Of these, 55 were male (111 eyes) and 47 were female (87 eyes). The ages of included patients ranged between 60 to 85 years with an average age of $(71.31 \pm 5.65)$ years. According to the nuclear hardness grading system for cataract lenses, there were 49 eyes of grade II, 55 eyes of grade III, 57 eyes of grade IV, and 37 eyes of grade V. Those that met the criteria of low vision after surgery were regarded as the low vision group $(n=75)$, while those that did not were regarded as the non-low vision group $(\mathrm{n}=123)$. Since there were no significant differences in the general information (such as age and physical condition) between the groups $(\mathrm{P}>0.05)$, they were comparable for other clinic data.

This study was approved by Affiliated Hospital of North Sichuan Medical College (No. 2020ER037-1). All procedures performed in this study involving human participants were in accordance with the Declaration of Helsinki (as revised in 2013). Individual consent for this retrospective analysis was waived.

\section{Research methods}

Clinical data of all patients were collected, including age, gender, preoperative corrected vision, history of glaucoma, lens nucleus hardness classification, vitreous turbidity, fundus lesions, postoperative corneal edema, postoperative corneal elastic layer folds, and phacoemulsification duration. Changes in visual function and quality of life were compared before and after treatment. A logistic regression model was used to analyze the risk factors that affect visual function of senile cataract patients following phacoemulsification, as well as the correlation between visual function and quality of life.

\section{Surgical methods}

All patients underwent phacoemulsification combined with intraoperative blue light filtering intraocular lens implantation, and all procedures were performed by the same surgeon using the same Phaco machine (Infiniti from Alcon, China). Briefly, the surface of the eye was initially anesthetized. A $6 \mathrm{~mm}$ reverse eyebrow scleral tunnel incision was then made $2 \mathrm{~mm}$ behind the limbus, which was separated with water. The nucleus of the lens 
was fragmented by one-handed in situ phacoemulsification to adsorb the residual cortex. The viscoelastic agent was injected into the anterior chamber and the capsular bag, and was then removed by injecting the intraocular lens into the capsular bag with an injector. The ultrasound capacity was set to $55 \%$, the suction pressure was set to $350 \mathrm{mmHg}$, and the ultrasound time was set to $8-60 \mathrm{~s}$.

\section{Observation indicators}

Low vision criteria (4) were defined according to the low vision diagnostic standards and classification methods in China: $0.1>$ best corrected visual acuity $\geq 0.05$ was considered the first-degree of low vision and $0.3>$ best corrected visual acuity $\geq 0.1$ was considered the second-degree of low vision. A low vision diagnosis was based on the postoperative visual acuity of $0.3>$ best corrected visual acuity $\geq 0.05$.

Visual function and QQL questionnaires developed by the US National Eye Institute for the clinical verification of cataract surgery in Aravind Eye Hospital in India were performed preoperatively, and at 3 days and 3 months postoperatively $(5,6)$. The questionnaire consisted of two parts. The first part was the visual function questionnaire comprising four types of indicators (subjective vision, peripheral vision, visual adaptation, and stereo vision). The quality of life questionnaire in the second part involved four types of vision-related indicators (self-care ability, mobility, social ability, and psychological status). According to the subjective feelings of the patients, answers to the questionnaire were divided into four levels ranging from no obvious difficulty to severe difficulty for each of the aforementioned indicators, and were scored between one and four points. After linear conversion, the scores of each item in each category of indicators were added to obtain the average score.

One investigator who had been previously trained conducted the questionnaire survey. When the investigator's survey-retest reliability reached 0.7 , the survey was initiated. The questionnaire was conducted in the physician's office and the investigator surveyed all patients. The participants' cultural cognition was taken into account to ensure that they had enough time to consider and answer the questions. A total of 102 questionnaires were distributed, and we achieved a recovery rate of $100 \%$.

\section{Statistical analysis}

Data were analyzed using the SPSS 20.0 statistical software
(IBM, USA). The measurement data were expressed as mean $\pm \mathrm{SD}$, and analyzed using the $\mathrm{F} / \mathrm{t}$ test. The count data were expressed as a percentage (\%), and analyzed using the Chi-square $\left(\chi^{2}\right)$ test. A logistic regression model was used to analyze the risk factors affecting visual function of senile cataract patients following phacoemulsification. Results with $\alpha=0.05$ were considered statistically significant.

\section{Results}

\section{Comparison of pre-and post-operative visual function}

The postoperative subjective vision, peripheral vision, visual adaptation, and stereo vision scores, as well as the total score of these items, at 3 days and 3 months were significantly higher than the preoperative scores $(\mathrm{P}<0.05)$. However, there was no statistical difference between the postoperative scores at 3 days and 3 months $(\mathrm{P}>0.05$, Table 1$)$.

\section{Comparison of pre-and post-operative quality of life}

The postoperative self-care ability, activity ability, psychological states, and social ability scores, as well as the total score of these items, at 3 days and 3 months were significantly higher than the preoperative scores $(\mathrm{P}<0.05)$. However, there was no statistical difference between the postoperative scores at 3 days and 3 months ( $\mathrm{P}>0.05$, Table 2).

\section{Single-factor analysis of visual function of senile patients with cataract following phacoemulsification}

There were no significant differences in the ages of the two groups $(\mathrm{P}>0.05)$. The number of patients with low postoperative vision who were aged $\geq 80$ years, and who had preoperative corrected visual acuity $<0.1$, a history of glaucoma, lens nucleus hardness grades of IV and V, moderate to severe vitreous turbidity, fundus disease, postoperative corneal edema, and postoperative corneal elastic fold was significantly greater than those with low postoperative vision who were $<80$ years old, and who had preoperative corrected visual acuity of 0.1 to 0.3 and $>0.3$, no history of glaucoma, lens nucleus hardness grades of II and III, mild vitreous turbidity, no fundus lesions, no postoperative corneal edema, and no postoperative corneal elastic fold $(\mathrm{P}<0.05)$. Also, the phacoemulsification duration of the low vision group was shorter than that of the nonlow vision group $(\mathrm{P}<0.05$, Table 3$)$. 
Table 1 Comparison of pre- and post-operative visual function scores (mean \pm standard deviation)

\begin{tabular}{|c|c|c|c|c|c|c|}
\hline Time & $\mathrm{n}$ & Subject perception & Peripheral visual field & Visual adaptation & Stereo vision & Total scores \\
\hline Pre-operation & 198 & $37.62 \pm 12.59$ & $39.63 \pm 17.58$ & $33.79 \pm 17.85$ & $39.84 \pm 14.33$ & $41.59 \pm 15.79$ \\
\hline $3 \mathrm{~d}$ after surgery & 198 & $70.51 \pm 14.61^{*}$ & $89.61 \pm 11.39^{*}$ & $79.86 \pm 15.91^{*}$ & $87.85 \pm 11.91^{*}$ & $89.53 \pm 10.31$ \\
\hline $\mathrm{F}$ & & 390.77 & 888.54 & 533.71 & 963.32 & 989.87 \\
\hline $\mathrm{P}$ & & $<0.001$ & $<0.001$ & $<0.001$ & $<0.001$ & $<0.001$ \\
\hline
\end{tabular}

Compared with pre-surgery, ${ }^{*} \mathrm{P}<0.05$.

Table 2 Comparison of pre- and post-operative quality of life scores (mean \pm standard deviation)

\begin{tabular}{lcccccc}
\hline Time & $\mathrm{n}$ & Self-care ability & Mobility & Psychological states & Sociability & Total scores \\
\hline Preoperative & 102 & $40.31 \pm 15.33$ & $43.51 \pm 12.69$ & $40.91 \pm 16.53$ & $37.51 \pm 14.52$ & $46.93 \pm 15.73$ \\
3 days postoperative & 102 & $85.91 \pm 11.71^{\star}$ & $87.61 \pm 13.21^{\star}$ & $89.59 \pm 10.37^{\star}$ & $83.59 \pm 11.36^{\star}$ & $88.71 \pm 10.65$ \\
3 months postoperative & 102 & $86.39 \pm 11.52^{\star}$ & $88.15 \pm 13.11^{*}$ & $90.51 \pm 10.51^{*}$ & $84.55 \pm 11.31^{\star}$ & $90.11 \pm 9.36$ \\
F & & 424.59 & 394.01 & 501.53 & 472.83 & 410.77 \\
P & & $<0.001$ & $<0.001$ & $<0.001$ & $<0.001$ & $<0.001$ \\
\hline
\end{tabular}

Compared with pre-surgery, ${ }^{*} \mathrm{P}<0.05$.

\section{Multi-factor analysis of the effects of phacoemulsification on visual function in senile cataract patients}

According to the analysis of the unconditional multivariate logistic regression model, age ( $\geq 80$ years), preoperative corrected visual acuity $(<0.1)$, a history of glaucoma, postoperative corneal edema, fundus disease, and a longer phacoemulsification time were all risk factors affecting the postoperative visual function of senile cataract patients $(\mathrm{P}<0.05$, Table 4).

\section{Analysis of the correlation between visual function and quality of life in senile cataract patients after phacoemulsification}

Results indicated that the visual function indexes, including subjective vision, peripheral visual field, visual adaptation, and stereo vision, of senile cataract patients following phacoemulsification were positively correlated with quality of life $(\mathrm{P}<0.05$, Table 5$)$.

\section{Discussion}

\section{Changes in visual function and quality of life after} phacoemulsification in senile cataract patients

Essentially, phacoemulsification involves an emulsifying needle with ultrasonic shock function entering the eye through a small incision, breaking the cataract, and exhaling it under high-frequency concussion. With the development of phacoemulsification technology, the improvement of surgical techniques, and the standardization of postoperative treatment, phacoemulsification has become the firstline treatment option for cataracts (7). Related research has found that phacoemulsification combined with IOL implantation could significantly improve intraocular pressure, macular fovea thickness, visual acuity, and visual quality in senile cataract patients (8). Our results indicate that the visual function and quality of life questionnaire scores of patients at any postoperative stage were higher than the preoperative scores $(\mathrm{P}>0.05)$, which confirms the effectiveness of phacoemulsification in improving the visual function and quality of life in senile cataract patients. However, there was no significant difference in VF and QQL scores on postoperative $3 \mathrm{~d}$ and 3 months after the surgery ( $P>0.05)$, indicating that the quality of life of the patients on postoperative $3 \mathrm{~d}$ was rapidly improved as the visual function, self-care ability, daily activities, social ability, psychological status and quality of life were rapidly improved, and remained unchanged within 3 months after the surgery.

\section{Risk factors affecting visual function of senile cataract patients following phacoemulsification}

Previous studies have reported that during phacoemulsification, 
Table 3 Single-factor analysis of the effects of phacoemulsification on the visual function of senile cataract patients

\begin{tabular}{|c|c|c|c|c|c|}
\hline Factors & Cases $(n=198)$ & Low vision group $(n=75)$ & Non-low vision group $(n=123)$ & $\chi^{2}$ & $\mathrm{P}$ \\
\hline Gender (n) & & & & 0.365 & 0.546 \\
\hline Male & 111 & 40 & 71 & & \\
\hline Female & 87 & 35 & 52 & & \\
\hline Age (year) & & & & 20.874 & $<0.001$ \\
\hline$\geq 80$ & 118 & 60 & 58 & & \\
\hline Preoperative vision correction & & & & 93.472 & $<0.001$ \\
\hline$>0.3$ & 81 & 5 & 76 & & \\
\hline $0.1-0.3$ & 75 & 30 & 45 & & \\
\hline No & 102 & 6 & 96 & & \\
\hline Lens nuclear hardness (n) & & & & 82.066 & $<0.001$ \\
\hline Grade II & 49 & 2 & 47 & & \\
\hline Grade III & 55 & 7 & 48 & & \\
\hline Grade IV & 57 & 37 & 20 & & \\
\hline Grade V & 37 & 29 & 8 & & \\
\hline Degree of vitreous turbidity (n) & & & & 83.133 & $<0.001$ \\
\hline No & 157 & 36 & 121 & & \\
\hline Fundus lesions (n) & & & & 114.913 & $<0.001$ \\
\hline Yes & 67 & 60 & 7 & & \\
\hline No & 131 & 15 & 116 & & \\
\hline $\begin{array}{l}\text { Postoperative corneal posterior } \\
\text { elastic fold ( } n \text { ) }\end{array}$ & & & & 58.032 & $<0.001$ \\
\hline Yes & 49 & 41 & 8 & & \\
\hline No & 149 & 34 & 115 & & \\
\hline Phacoemulsification time (s) & - & $54.39 \pm 4.69$ & $35.31 \pm 5.91$ & 23.760 & $<0.001$ \\
\hline
\end{tabular}


Table 4 Multi-factor analysis of the effects of phacoemulsification on the visual function of senile cataract patients

\begin{tabular}{|c|c|c|c|c|c|}
\hline Factors & Regression coefficient & SEM & Wald $\chi^{2}$ & $\mathrm{P}$ & OR $(95 \% \mathrm{Cl})$ \\
\hline $\begin{array}{l}\text { Preoperative vision correction }<0.1 \text { (Control group: } \\
0.1-0.3 \text { or }>0.3 \text { ) }\end{array}$ & 0.763 & 0.143 & 4.569 & $<0.001$ & $2.14(1.62-2.84)$ \\
\hline With a history of glaucoma (Control group: No) & 0.851 & 0.179 & 4.813 & $<0.001$ & $2.34(1.65-3.33)$ \\
\hline $\begin{array}{l}\text { Moderate to severe vitreous turbidity (Control group: } \\
\text { Mild) }\end{array}$ & 0.893 & 0.791 & 4.981 & 0.911 & $2.44(0.52-11.51)$ \\
\hline Postoperative corneal edema (Control group: No) & 0.845 & 0.169 & 4.834 & $<0.001$ & $2.33(1.67-3.24)$ \\
\hline Fundus lesions (Control group: No) & 0.877 & 0.117 & 4.791 & $<0.001$ & $2.40(1.91-3.02)$ \\
\hline
\end{tabular}

SEM, standard error of mean.

Table 5 Analysis of the correlation between visual function and quality of life in senile cataract patients following phacoemulsification

\begin{tabular}{lcc}
\hline \multirow{2}{*}{ Independent variable } & \multicolumn{2}{c}{ QQL score } \\
\cline { 2 - 3 } & $\mathrm{r}$ & $\mathrm{P}$ \\
\hline Subjective vision & 0.751 & 0.013 \\
Peripheral visual field & 0.791 & 0.017 \\
Visual adaptation & 0.821 & 0.029 \\
Stereo vision & 0.746 & 0.009 \\
\hline
\end{tabular}

QQL, quality of life scale.

doctors are required to extract extracapsular cataracts, which can easily damage the corneal endothelial cells, causing increased corneal astigmatism and changing the density and central corneal thickness of corneal cells. Therefore, the postoperative loss of vision is the most severe potential complication for all patients following phacoemulsification (9). To solve this problem, it is prudent to understand the risk factors that affect the occurrence of poor vision following phacoemulsification. So, in this study, we analyzed the risk factors for low postoperative vision and offered some preventive measures.

\section{Preoperative factors}

Fundus diseases primarily comprise macular thinning and vitreous turbidity, which can affect vision after cataract surgery by causing retinal vascular lesions in the macular area (10). In total, 67 eyes included in this study had fundus lesions. Analysis of the unconditional multivariate logistic regression model showed that fundus lesions were risk factors affecting the visual function of senile cataract patients following phacoemulsification $(\mathrm{P}<0.05)$. Therefore, maximum mydriasis should be ensured in the preoperative stage, and the fundus should be examined in detail to evaluate the prognosis of the patient (11).

Cataract patients with glaucoma can experience abnormally increased intraocular pressure, severe damage to corneal endothelial cells, aggravation of postoperative corneal edema, and poor vision after surgery (12). Therefore, the intraocular pressure of cataract patients with preexisting glaucoma needs to be actively control (with antiglaucoma surgery if necessary) to reduce early postoperative visual damage.

\section{Postoperative complications}

The results of the unconditional multivariate logistic regression model analysis showed that postoperative corneal edema and a longer phacoemulsification time were risk factors that affect the visual function of senile cataract patients following phacoemulsification $(\mathrm{P}<0.05)$. The incidence of corneal edema is closely related to multiple factors during surgery including: (I) mechanical stimulation, (II) excessive ultrasound power in close proximity to the corneal endothelium, and prolonged surgery duration; 
and (III) foreign bodies such as cotton fiber, viscoelastic agents, lens cortex, and capsule fragments may adhere to the corneal endothelium and affect the metabolism of the corneal cortex (13). Thus, in order to avoid complications such as corneal edema, it is necessary to ensure proficiency of the surgeon and shorten surgery duration to reduce damage to endothelial cells.

\section{Lens core hardness}

Generally, the greater the hardness of the lens nucleus, the stronger the ultrasonic energy and the longer the surgery time required for phacoemulsification in the treatment of cataracts. Ultrasonic concussion, energy burns, and mechanical damage can cause changes to the intraocular microenvironment, result in disturbance of the retina and corneal endothelium. Moreover, they can also lead to an increased incidence of complications such as postoperative infection, corneal edema, and macular edema, which ultimately result in poor postoperative vision (14). Multivariate regression analysis found that the hardness of lens nucleus above grade IV is an independent risk factor for low vision after surgery, and thus, the hardness of lens nuclear should be considered as an important factor before surgery.

\section{Age}

The results of this study showed that age ( $\geq 80$ years) is an independent risk factor for low vision after surgery. This was unsurprising, considering that the ocular tissue is significantly degenerated in elderly patients due to the physiological decrease in the number of corneal endothelial cells. Furthermore, elderly patients typically suffer from systemic and fundus diseases, as well as poor surgical tolerance, poor postoperative healing ability, more complications, and slower recovery of vision (15). Therefore, strengthening the health education and understanding of cataracts among elderly people is necessary. At the same time, preoperative preparation and evaluation are also required.

Also, we analyzed the correlation between visual function and the quality of life in senile cataract patients following phacoemulsification. We found that various indicators of visual function were positively correlated with quality of life $(\mathrm{P}<0.05)$, suggesting that poor visual function has an effect on the psychological and social activities of cataract patients.

In summary, phacoemulsification can improve the short- term visual function and quality of life of senile cataract patients. Advanced age, preoperative corrected vision $(<0.1)$, a history of glaucoma, postoperative corneal edema, fundus lesions, and a longer phacoemulsification time are risk factors impacting the visual function in senile cataract patients following phacoemulsification. For patients with these high-risk factors, clinical intervention and evaluation are needed to reduce the risk of low vision following phacoemulsification. With the extension of the time after surgery, the improved quality of life and the visual function of the operative eye can be affected by many factors and then might decline again. Therefore, the follow up of this study only observed 3 months after surgery, and the maintenance or change trend of the visual function and the quality of life for a longer period after surgery remains to be further studied.

\section{Acknowledgments}

Funding: None.

\section{Footnote}

Reporting Checklist: The authors have completed the MDAR reporting checklist. Available at http://dx.doi.org/10.21037/ apm-20-1709

Data Sharing Statement: http://dx.doi.org/10.21037/apm20-1709

Conflicts of Interest: Conflicts of Interest: All authors have completed the ICMJE uniform disclosure form (available at http://dx.doi.org/10.21037/apm-20-1709). The authors have no conflicts of interest to declare.

Ethical Statement: The authors are accountable for all aspects of the work in ensuring that questions related to the accuracy or integrity of any part of the work are appropriately investigated and resolved. This study was approved by Affiliated Hospital of North Sichuan Medical College (No. 2020ER037-1). All procedures performed in this study involving human participants were in accordance with the Declaration of Helsinki (as revised in 2013). Individual consent for this retrospective analysis was waived.

Open Access Statement: This is an Open Access article distributed in accordance with the Creative Commons Attribution-NonCommercial-NoDerivs 4.0 International 
License (CC BY-NC-ND 4.0), which permits the noncommercial replication and distribution of the article with the strict proviso that no changes or edits are made and the original work is properly cited (including links to both the formal publication through the relevant DOI and the license). See: https://creativecommons.org/licenses/by-nc-nd/4.0/.

\section{References}

1. Gupta S, Selvan H, Khokhar S. Hook and flip technique: for phacoemulsification in non-rotating nuclei and posterior polar cataracts. Int Ophthalmol 2019;39:1219-23.

2. Olson RJ, Braga-Mele R, Chen SH, et al. Cataract in the Adult Eye Preferred Practice Pattern®. Ophthalmology 2017;124:P1-119.

3. Rasul A, Kessel L. Prevalence of anterior polar cataracts in children and risk factors for amblyopia. Acta Ophthalmol 2019;97:486-90.

4. Akintunde JK, Akintola TE, Hammed MO, et al. Naringin protects against Bisphenol-A induced oculopathy as implication of cataract in hypertensive rat model. Biomed Pharmacother 2020;126:110043.

5. Daszynski DM, Santhoshkumar P, Phadte AS, et al. Failure of Oxysterols Such as Lanosterol to Restore Lens Clarity from Cataracts. Sci Rep 2019;9:8459.

6. Phadte AS, Mahalingam S, Santhoshkumar P, et al. Functional Rescue of Cataract-Causing $\alpha \mathrm{A}-\mathrm{G} 98 \mathrm{R}-$ Crystallin by Targeted Compensatory Suppressor Mutations in Human aA-Crystallin. Biochemistry 2019;58:4148-58.

Cite this article as: He L, Cui Y, Tang X, He S, Yao X, Huang Q, Lei H, Li H, Liao X. Changes in visual function and quality of life in patients with senile cataract following phacoemulsification. Ann Palliat Med 2020;9(6):3802-3809. doi: 10.21037/apm-20-1709
7. Aptel F, Colin C, Kaderli S, et al. Management of postoperative inflammation after cataract and complex ocular surgeries: a systematic review and Delphi survey. $\mathrm{Br}$ J Ophthalmol 2017;101:1-10.

8. Liew G, Strong S, Bradley P, et al. Prevalence of cystoid macular oedema, epiretinal membrane and cataract in retinitis pigmentosa. $\mathrm{Br} J$ Ophthalmol 2019;103:1163-6.

9. Patel N, Anand D, Monies D, et al. Novel phenotypes and loci identified through clinical genomics approaches to pediatric cataract. Hum Genet 2017;136:205-25.

10. Xu W, Kurup SP. Pediatric Anterior Pyramidal Polar Cataract. JAMA Ophthalmol 2017;135:e171441.

11. Rasul A, Kessel L. Prevalence of anterior polar cataracts in children and risk factors for amblyopia. Acta Ophthalmol 2019;97:486-90.

12. Li G, Song H, Chen L, et al. TUG1 promotes lens epithelial cell apoptosis by regulating miR-421/caspase-3 axis in age-related cataract. Exp Cell Res 2017;356:20-7.

13. Titiyal JS, Kaur M, Falera R. Intraoperative optical coherence tomography in anterior segment surgeries. Indian J Ophthalmol 2017;65:116-21.

14. Moravikova J, Dudakova L, Kozmik Z, et al. Familial aniridia spectrum in four families of Czech origin with PAX6 mutations. Acta Ophthalmologica 2019;97:1666-8.

15. Phadte AS, Santhoshkumar P, Sharma KK. $\alpha$ A-crystallinderived minichaperone stabilizes $\alpha$ AG98R-crystallin by affecting its zeta potential. Mol Vis 2018;24:297-304.

(English Language Editor: A. Kassem) 